\title{
LO CONSTITUCIONAL
}

\author{
José Ramón Cossío Díaz \\ El Colegio de México
}

\section{EL ENCARGO}

Dara este número celebratorio se me encargó dar cuenta de lo 1 contenido en Historia Mexicana (HM) en materia constitucional. La petición me pareció sensata y atractiva y su ejecución simple e interesante. Ello, hasta que comencé a pergeñar la tarea. Tenía frente a mí numerosos ejemplares que revisar. Ante este reto puramente cuantitativo, se abrió otro más preocupante. El del criterio a seguir para identificar, dentro de la enorme masa de colaboraciones publicadas, las que tuvieran carácter "constitucional”. ¿Debía cuantificar el material, periodizarlo, describirlo, criticarlo o tratar de hacer todo ello simultáneamente? Lo que parecía un encargo simple, comenzó a requerir de un método.

\section{EL MÉTODO}

Historia Mexicana comenzó a publicarse en 1951 y al momento de escribir esta nota han aparecido 277 números. Cada uno de ellos se compone de secciones -artículos, reseñas, entrevistas y comentarios- más o menos constantes. Asumiendo que se me 
había requerido dar cuenta de alguna manera de la parte sustantiva, me concentré en los artículos. Según mi propia contabilidad, en las 1362 colaboraciones realizadas a lo largo de 70 años. Imaginé desplegados ante mis ojos ese número de posibilidades todavía sin distinguir, a fin de poder determinar a cuáles les daría atención particularizada por tener carácter "constitucional”. Apareció un nuevo problema: identificar cuáles de entre esas posibilidades eran pertinentes.

Me surgieron dos preguntas. Primera, ¿qué iba a asumir por "constitucional" en abstracto? Segunda, ¿cómo iba a aplicar el concepto respecto de los artículos de una revista de historia general de México? Tenía que decidir si iba a imponer mi carácter de profesional del derecho para identificar los materiales a trabajar o si, por el contrario, iba a confiar en el criterio propio de $H M$. En el primer caso, mi tarea consistiría en decir algo así como "para mí lo 'constitucional' es esto y, por lo mismo, los artículos con los que voy a trabajar únicamente serán éstos”. En el segundo caso, tendría que asumir que, si un autor le asigna a un tema, acontecimiento o persona el carácter de "constitucional", debería hacer de su estudio el objeto de mi análisis.

La resolución de este dilema pasa por definir la vieja tensión entre el derecho y la historia. ¿Es la historia del derecho un quehacer de juristas metidos a historiadores o es, por el contrario, la tarea de historiadores especializados? Si es lo primero, debería hacer prevalecer mi enfoque jurídico sobre el contenido de $H M$. $\mathrm{Si}$ es lo segundo, debería asumir los criterios de los historiadores para, al menos, trabajar con los materiales que a ellos les parezcan "constitucionales", más allá de si para mí lo son.

Ante la dificultad de resolver tan añeja cuestión con base en un criterio objetivo, he optado por hacerlo con uno subjetivo, que no arbitrario. Se me invitó a colaborar en este análisis por lo que soy. Por lo mismo, supongo que se asumió que serían los criterios propios de mi profesión los que guiarían mis investigaciones. Con base en ellos identificaré los materiales para trabajar. 
¿A qué se refiere un jurista con el término "constitucional"? Estrictamente, a dos cosas: a lo vinculado jurídicamente con una constitución, en buena medida por formar parte de ella, así como a las normas que siendo de jerarquía inferior no la contradicen. Ejemplos de lo primero son expresiones tales como derechos o facultades constitucionales, para aludir a la libertad de expresión o a la posibilidad de presentar leyes, respectivamente. Ejemplos de lo segundo, son el reconocimiento de que una ley de ingresos no viola el artículo 73 constitucional, o que la sentencia de un juez penal es contraria al artículo 14 del mismo texto.

Si $H M$ fuera una revista de historia del derecho, lo correcto hubiera sido identificar todos los artículos en los que se hubiera desarrollado el sentido jurídico de lo "constitucional". Probablemente contaríamos con la identificación de las maneras en las que diversos órganos o juristas consideraron que en un largo periodo -asunto al que enseguida volveremos- se determinó la invalidez de normas o se desarrollaron temas como los mencionados. Sin embargo, la utilización de ese criterio para identificar los materiales contenidos en una revista de historia general resulta en la imposición de una categoría externa. Sería tanto como decir, finalmente, que sólo vamos a considerar como trabajo pertinente a lo "constitucional", aquel que se haga de modo jurídico.

Para salir de esta evidente limitación, propongo otro camino. Consideraré como "constitucional" todo desarrollo que se realice respecto de temas vinculados con la constitución. Ello impone nuevas precisiones. Independientemente de que existan antecedentes narrados por Aristóteles o Polibio sobre el uso y las prácticas del término, existe consenso entre los juristas de que las constituciones aparecen a partir de finales del siglo XvIII y comienzos del xix, con expresiones tales como la de Virginia, la federal estadounidense o las francesas que le siguieron. Si ello es así, lo "constitucional" tendrá que ser expresiones de diversos tipos vinculadas con esas construcciones históricas y no, por 
ejemplo, con la Carta Magna inglesa o las Siete Partidas, por importantes que en sí mismas puedan ser.

La base de la cual se tendría que partir, entonces, es que habría que identificar como "constitucional" a las normas supremas emitidas a partir de esos años, para regir en condiciones de supremacía respecto a la creación del resto de las normas componentes del correspondiente orden jurídico nacional. Esto define que sería factible considerar todos aquellos trabajos que directamente trataron de las constituciones como ordenamientos, las ideas que les dieron sustento, los procesos que las posibilitaron, los trabajos llevados a cabo para establecerlas y las maneras en las que se implementaron. Igualmente, sería adecuado considerar aquellos trabajos en los que se desarrollaron, en cualquiera de las modalidades acabadas de señalar-ideas, procesos, etc.-, aspectos concretos tales como la división de poderes, un derecho humano, la jurisdicción del estado o cualquier otra institución con ella relacionada. Este criterio posibilita identificar los ejercicios que, en forma de artículo, historiadores especializados y no especializados en derecho han realizado a partir de 1951 en $H M$ para dar cuenta de, en principio, la gran cantidad de temas que suelen estar vinculados con el constitucionalismo y las constituciones: derechos humanos, estado de excepción, ciudadanía, elecciones, sistema federal, división de poderes, órganos de gobierno -legislativo, ejecutivo y judicial-, responsabilidad pública, entidades federativas, municipios y reformas constitucionales, destacadamente. Vamos a ello.

\section{EL DESARROLLO}

El análisis de los trabajos publicados en las condiciones indicadas lo realizaré desde los puntos de vista cuantitativo y cualitativo. Con el primero, buscaré identificar cuáles de entre todos los artículos publicados en HM tienen que ver con lo "constitucional”. A partir de ahí, también, sus métricas de distribución 
conforme a los criterios que luego expondré. Mediante el segundo, analizaré los temas tratados a fin de determinar si hay patrones, tendencias u otros elementos comunes al conjunto.

\section{Datos}

Para identificar el número de artículos publicados en $H M$ sobre temas vinculados con lo "constitucional", tengo que aplicar el criterio ya determinado. Esta operación arroja como resultado preliminar que, de las 1362 posibilidades, sólo 65 casos parecen satisfacerlo. Recalco el parecen, pues, así como hay algunos evidentes -como el publicado en 1951 por List acerca del Constituyente de 1917-, otros se encuentran en una zona de más difícil identificación -como el publicado en 2019 por Brondino sobre la conformación de la autoridad en Yucatán en el siglo xix.

La dificultad señalada no es tanto de criterio, sino de la manera en que lo "constitucional" se desarrolla en los trabajos. Una cosa es hacer reflexión jurídica sobre lo jurídico, y otra muy distinta es considerar un tema jurídico para explorar sus dimensiones sociales o políticas. Ejemplifico. En 1960 Hilario Medina escribió un artículo en el que identificó las contribuciones de Emilio Rabasa a la Constitución de 1917. Por otra parte, Romana Falcón publicó en 2005 un artículo en que analiza las reacciones del estado liberal frente a las rebeliones populares surgidas entre 1867 y 1876 . Aun cuando por denominación ambos artículos se refieran al estado, o más en general a lo público, en el primer caso hay un análisis de pensamientos con una clara incidencia en lo "constitucional", mientras que en el segundo se desarrollan con amplitud y profundidad los aspectos políticos de la cuestión.

Si ajusto los 65 casos iniciales a fin de dejar fuera los dudosos, ${ }^{1}$ en $H M$ se han publicado 54 artículos en los que lo

${ }^{1}$ Quirk (36), 1960, pp. 571-581; Berzunza (46), 1962, pp. 274-295; Sмith (74), 1969, pp. 189-227; Falcón (114) 1979, pp. 197-240; Campos García 
“constitucional” ha sido el objeto de estudio. ${ }^{2}$ En términos porcentuales, $3.9 \%$ de los artículos han versado sobre la materia “constitucional”. Esto ya es un indicador de, al menos, el poco interés que los estudios constitucionales despiertan en los historiadores profesionales o del poco interés o falta de posibilidades de los historiadores jurídicos para publicar en revistas de historia general.

(201), 2001, pp. 59-102; Falcón (216), 2005, pp. 973-1048; Carrillo (216), 2005, pp. 1049-1103; Teitelbaum (220), 2006, pp. 1221-1287; Loaeza (249), 2013, pp. 251-358; Brondino (272), 2019, pp. 1463-1538; Aguilar Rivera (273), 2019, pp. 7-56.

2 List Arzubide (2), 1951, pp. 227-250; Villoro (6), 1952, pp. 223-239; Scholes (7), 1953, pp. 343-352; Quirk (8), 1953, pp. 503-528; Sepúlveda (29), 1958, pp. 1-34 y (30), 1958, pp. 145-174; Fuentes Mares (33), 1959, pp. 1-14; Medina (38), 1960, pp. 176-195; Bazant (38), 1960, pp. 220-243; Mesa (39), 1961, pp. 439-460; GonZález Navarro (40), 1960, pp. 628-636; FuenTes Mares (55), 1965, pp. 423-444; Ross (58-59), 1965-1966, pp. 425-445); Macías (73), 1969, pp. 11-22; Macías (80), 1971, pp. 511-521; Smith (87), 1973, pp. 363-395; Meyer (92), 1974, pp. 722-752); Richmond (101), 1976, pp. 107-131; González Navarro (104), 1977, pp. 503-539; Meyer (126), 1982, pp. 143-197; KNIGHT (137), 1985, pp. 59-91; GonZÁLEZ Uribe (145), 1987, pp. 136-137; González Navarro (153), 1989, pp. 297-312; Loyo (158), 1990, pp. 299-336; Rodríguez O. (159), 1991, pp. 507-535; LoAEZA (177), 1995, pp. 99-158; Knowlton (181), 1996, pp. 71-98; Diego-FernánDez (19), 1998, pp. 3-35; Del Arenal Fenochio (189), 1998, pp. 37-70; Knowlton (189), 1998, pp. 71-96; Hale (19), 1998, pp. 97-125; CÁrdenas Gutiérrez (191), 1999, pp. 523-566; Marván Laborde (202), 2001, pp. 261-323; Forte (212), 2004, pp. 863-910; Uhthoff (213), 2004, pp. 129-178; Anaya (214), 2004, pp. 365-403; González Navarro (219), 2006, pp. 947-972; López González (220), 2006, pp. 1289-1351; MARINO (220), 2006, pp. 1353-1410; SPECKMAN (220), 2006, pp. 1411-1466; ANDREws (221), 2006, pp. 71-116; Pantoja (228), 2008, pp. 1045-1106; Annino (229), 2008, pp. 179-227; Ávila (233), 2009, pp. 77-116; Trejo (235), 2010, pp. 877-917; Mac Gregor (238), 2010, pp. 1119-1174; Cáceres (242), 2011, pp. 477-530; Aguilar Rivera (242), 2011, pp. 531-588; Coudart (258), 2015, pp. 629-687; Mijangos (261), 2016, pp. 7-64; SErrano Ortega (265), 2017, pp. 169-231; Andrews (272), 2019, pp. 1539-1592; DuCEy (272), 2019, pp. 1593-1638; GinZBerg (274), 2019, pp. 551-611. 
¿Qué otros datos nos arrojan los 54 artículos identificados? Vistos en décadas de publicación, que en cada una de las dos iniciales se publicaron 7 artículos, en las dos siguientes hubo una caída importante (5 y 4), y en las tres finales se dio un incremento, si no constante, sí al menos notable -de 9, 12 y 10 , respectivamente-. A pesar de que en los años sesenta y en los primeros diez del siglo xx hubo celebraciones en materia constitucional -los primeros 100 años de la independencia y los primeros 50 de la Constitución de Querétaro y, luego, los 200 de la independencia y los 100 de ese mismo texto-, no se aprecia el incremento de artículos de temporada.

En cuanto a los temas abordados y partiendo de una temporalidad general, resulta que la mayor parte tienen que ver con la Reforma, la Constitución de 1857, el porfiriato, la Revolución, el Constituyente y la Constitución del 17, la aplicación de ésta y las constituciones nacionales en general -con respecto a la independencia, el primer imperio, la Constitución de 1824 y el centralismo-, prácticamente en una proporción de 4 a 1. Esta diferencia es más acentuada si relacionamos los temas tratados con la geografía político-jurídica. De los 54 artículos, 3 se refieren a la ciudad de México, 3 a las entidades federativas y el resto a temas estrictamente nacionales o federales.

Otros datos que pueden obtenerse son los relativos a la distribución de los temas tratados, asunto que por lo demás se sobrepone en parte a los temas cualitativos que enseguida analizaré. ¿Hay, en efecto, algún tipo de concentración temática en relación con los años en que se publicó $H M$ ? La respuesta es que no, pues no hay concentraciones, por decirlo así, entre artículos vinculados con lo "constitucional" en la independencia o en la revolución respecto a ciertos tiempos o periodicidades. Lo único que existe es la publicación de dos números monográficos en materia jurídica en general, pero no "constitucional" en particular. En el primero de ellos, se escribió de fray Servando, el significado de la constitución para Iturbide, el ejido en el siglo XIX 
y el legado de Rabasa; ${ }^{3}$ en el segundo, se desarrollaron temas vinculados con la justicia desde la colonia hasta comienzos del siglo $\mathrm{xx}$, sin existir relación con el tiempo de su publicación. ${ }^{4}$

\section{Temas}

El análisis material de los 54 artículos publicados en $H M$ acerca de lo "constitucional" puede realizarse de diversas maneras. La primera, identificando los temas para tener un panorama de todo lo que al respecto se ha escrito. Al hacerlo, ${ }^{5}$ resulta fácil advertir

3 (189), 1998.

4 (220), 2006.

${ }^{5}$ Para no repetir, únicamente mencionaré el primer apellido del autor pues la identificación de su publicación está mencionada en la nota 2. El trabajo del Constituyente de 1917 (Arzubide); el pensamiento de Hidalgo (Villoro); el liberalismo reformista (Scholes); las corrientes ideológicas en la revolución (Quirk); las fronteras nacionales (Sepúlveda); el subsuelo (Fuentes); Rabasa en el Constituyente de 1917 (Medina); las revoluciones mexicanas (Bazant); la reforma agraria (Mesa); la ideología de le revolución mexicana (González); la convocatoria de 1867 (Fuentes); la revolución mexicana (Ross); la Constitución de Apatzingán (Macías); el constituyente de 1917 (Smith); el estado mexicano contemporáneo (L. Meyer); el nacionalismo de Carranza (Richmond); el régimen de las tierras ociosas (González); las elecciones presidenciales (Meyer); el liberalismo mexicano (Knight); el maderismo y la revolución (González); las relaciones laborales en la Constitución de 1917 (González); las escuelas rurales (Loyo); la Constitución de 1824 (Rodríguez); la historia política del Distrito Federal (Loaeza); los tribunales en el siglo XIX (Knowlton); la influencia del pensamiento de fray Servando (Diego-Fernández); la idea de constitución para Iturbide (Del Arenal); el ejido mexicano en el siglo xix (Knowlton); el legado de Rabasa (Hale); el imaginario social de la república restaurada (Cárdenas); la XXVIII Legislatura (Marván); los orígenes del poder coactivo en México y Argentina (Forte); el régimen fiscal (Uhthoff); la reelección (Anaya); la ley Juárez (González); el imaginario monárquico en el segundo imperio (López); la cultura jurídica campesina en el segundo imperio (Marino); la justicia en la ciudad de México (Speckman); la reforma constitucional en la presidencia de Bustamante (Andrews); el parlamentarismo en la Constitución de 1857 (Pantoja); el imperio y la constitución en América hispana (Annino); los debates en torno al gobierno de la Nueva España en la independencia (Ávila); 
que los mismos no arrojan un patrón constante. En realidad, hay un poco de todo en el arco que va de los inicios de la independencia a la aplicación de la Constitución de 1917. Hagamos otros intentos.

$¿$ Es posible identificar algunas maneras de tratar los temas mencionados más allá de la ya señalada variedad? Me parece que sí. Los artículos iniciales (Arzubide, Villoro, Scholes, Quirk, Medina, González, Mesa y Fuentes Mares, por ejemplo), tenían un estilo más retórico, tanto que pareciera que estaban tratando de construir el objeto de estudio más que describirlo. Demostrar que la Constitución de 1917 era de por sí revolucionaria porque provenía de un movimiento social, o que Hidalgo tuvo siempre claridad en que lo suyo era encabezar un movimiento popular. A diferencia de esos trabajos iniciales otros, incluso de los mismos autores (González, por ejemplo), tienen un desarrollo más expositivo. Un hacer en el que no resultaba tan evidente la necesidad de demostrar.

Por lo demás, el análisis del conjunto no me lleva a identificar cambios en los métodos utilizados ni en los modos de construcción de los objetos de estudio. En cuanto a lo primero, no hay, por señalar sólo dos posibilidades, algo que indique que antes -o ahora- se hacía un uso más amplio de fuentes originarias frente a un uso más extensivo de las historiográficas. Creo que existe una mezcla más o menos constante entre unas y otras y no rupturas o cambios significativos. Respecto al segundo asunto, tampoco observo que entre el pasado y el más cercano presente se hubieran introducido modos diferenciados de crear el objeto de estudio mediante el uso de narrativas, fuentes o modelos. Lo

la Constitución de Sonora (Trejo); las elecciones federales de 1920 y 1922 (MacGregor); las elecciones en Querétaro en la primera mitad del siglo XIX (Cáceres); el congreso extraordinario de 1846 (Aguilar); la libertad de prensa (Coudart); la suspensión del fuero eclesiástico (Mijangos); las instituciones en la independencia (Serrano); el legado de las Siete Leyes (Andrews); las elecciones en tiempos insurgentes (Ducey) y la reforma agraria (Ginzberg). 
que el conjunto muestra es la existencia-dejando de lado el tema apuntado en el párrafo anterior- de continuidades en el modo general de abordar los respectivos temas. Esta observación abre otra posibilidad de exploración.

$\mathrm{Si}$, en efecto, existe una cierta continuidad en los modos de analizar los temas relacionados con lo "constitucional”, ¿qué lo explica? La respuesta que se me ocurre es que el hecho de que el correspondiente autor haya querido explicarse la relación de algo en o con respecto a la constitución, le impone la carga de considerar de algún modo normas o prácticas jurídicas. Es decir, procesos institucionalizados con unas formas más o menos previsibles de desarrollo. A diferencia de otros estudios históricos en donde en muchas ocasiones hay que comenzar por determinar lo que es el objeto de estudio, en los estudios históricos relativos al derecho hay ya, por decirlo así, una institucionalidad, si no previa y por completo determinada, sí al menos dibujada en sus contornos. Lo que sea una autoridad o una institución no es algo que el historiador tenga que determinar por sí mismo, en tanto una u otra está ya más o menos identificada desde o por el derecho mismo.

Lo anterior no significa que quien trabaje con el derecho tenga por virtud de él la determinación de lo que es desde ya el fenómeno a estudiar. Simplemente significa que cuenta con un punto de partida. Con él podrá determinar diversos ángulos de observación para, por ejemplo, referirse a la constitución de las normas o de las prácticas, sus creadores o participantes, sus efectos sociales o las razones de su extinción.

Si bien las condiciones institucionalizadas del objeto generan una posibilidad más o menos constante de exploración, existen dos modalidades de acercamiento a él que quedan claras en los artículos de $H M$. De una parte, están los trabajos de quienes -los menos- hacen historia de lo "constitucional” con énfasis en lo jurídico o, si se quiere, en lo de por sí institucional. Quienes buscan entender los significados de las normas o de las prácticas 
constitucionales en un determinado momento o en tales o cuales circunstancias históricas. Es el caso de los trabajos de César Sepúlveda, algunos de los de Fuentes Mares (núm. 55, 1965), Knowlton (núm. 181, 1996), Uhthoff o Pantoja, por ejemplo. En este modo de proceder no se da una relación directa entre el bagaje del autor y el modo de tratamiento, pues aun cuando Sepúlveda o Pantoja tuvieron formación jurídica, otros autores no ni, por lo demás, en otros trabajos ellos mismos siguieron el mismo enfoque.

Lo que quiero poner en claro es que en los estudios históricos de lo "constitucional" existen dos modos de abordaje. En uno, las normas o las prácticas jurídicas son objeto de estudio en su devenir o en un cierto momento histórico, mientras que en otros se considera la manera en la que tales momentos determinaron esas normas o prácticas. Por ejemplo, en los trabajos de Arzubide, Medina, Bazant, Smith, Meyer (núm. 126, 1982) o Rodríguez, hay análisis muy importantes acerca de las condiciones en las que operaron los congresos o se dieron ciertos procesos determinados por el derecho. Sin embargo, en los de Sepúlveda, Fuentes (1965, núm. 55), González Navarro (núm. 104, 1977; núm. 153, 1989), Speckman (núm. 220, 2006), Mijangos o Andrews (núm. 272, 2019), el énfasis está puesto en el entendimiento del derecho -normas y prácticas- en determinado momento o periodo.

Para resumir las anteriores observaciones, cabe decir que una cosa es hacer historia del derecho y otra explicar la presencia del derecho en la historia. Dado que $H M$ es una revista general, es comprensible que el segundo tipo de análisis prevalezca sobre los primeros. Esto no tiene nada de particular si consideramos que exactamente lo contrario es lo que acontece en las revistas en las que en condiciones históricas se analizan normas, instituciones o prácticas jurídicas. En donde por razones académicas o profesionales, importa saber qué orígenes, sentidos o alcances tuvieron cada una de ellas. 
La revisión de los artículos publicados durante 70 años en $H M$ arroja datos interesantes, algunos ya adelantados en renglones anteriores. Lo primero que llama la atención es el escaso número de artículos dedicados a lo "constitucional". A pesar de la amplitud del criterio clasificatorio, apenas alcanza el 3.9\%. Ello es significativo si consideramos la atención que, en la misma revista, en El Colegio de México y en el país en general, se le dedicó a la triada independencia-reforma-revolución y lo que para las mismas tuvieron de importancia el derecho constitucional y sus derivados.

En relación con lo anterior, llama también la atención que los estudios en la materia hayan sido, en buena medida, tomándola más como referente de estudio que como objeto en sí mismo. Lo "constitucional", ahí donde apareció, fue más el telón de fondo o el contexto de la exposición que el objeto de estudio. A quienes escribieron de estos temas les pareció más importante saber cuáles eran las corrientes de opinión o los procesos políticos que dieron lugar a tal o cual norma o práctica jurídica, que saber cuál fue su génesis o su sentido normativo específico.

Lo que estas reflexiones finales muestran es que, con todas las limitaciones que tiene extraer conclusiones de una sola revista, a los historiadores que escriben de México no les ha parecido muy importante, ya no digamos hacer historia del derecho, sino más modestamente, conocer los aspectos jurídicos de los temas que han estudiado.

Esta observación abre una nueva pregunta: ¿cuáles son las razones de ese alejamiento? Desde luego no veo, en el modo de hacer las cosas, un desprecio por el derecho, pues ello implicaría una actitud activa hacia él, emitida a manera de descalificaciones de algún tipo. Más bien veo, aun en aquellos trabajos que buscaron considerar aspectos vinculados con el derecho -como es lo "constitucional"-, una falta de atención a las particularidades 
jurídicas. Esto, a su vez, puede tener dos explicaciones. La primera, que los historiadores no cuenten con el entrenamiento necesario para identificar al derecho, sus funciones y las maneras en las que permea en los fenómenos bajo su estudio. La segunda, que estimen, como sucedía con los manuales de divulgación marxista, que el mismo es una mera superestructura, un mero derivado de otros fenómenos. Si el problema fuera el primero, bastaría con corregir algo en el proceso de formación de los historiadores a fin de proporcionarles nuevas herramientas de trabajo; si fuera lo segundo, sería necesario realizar un esfuerzo más completo, para mostrarles la función social -además de la jurídica, desde luego- de las normas.

Por evidente que parezca, cualquiera de estos esfuerzos tiene que pasar por un ejercicio de reflexión de los propios historiadores a fin de que, por sí mismos, comprendan la importancia de introducir el punto de vista jurídico en sus trabajos. Luego, deseablemente, la necesidad de adquirir las habilidades para desarrollarlo. Si el camino se intenta de otra manera, me temo, los propios historiadores considerarán que hay esfuerzos intervencionistas por parte de los juristas o, lo que sería igualmente grave, intentos por volver a aquellos tiempos cuando los abogados hacían de todo -desde luego historia- por la falta de desarrollo de otros cuerpos académicos.

Sin querer incurrir en el pecado apuntado, me parece que una buena parte de los estudios históricos ganarían fuerza y profundidad si, así sea como marco general, quedaran claras las condiciones jurídicas de aquello que se está analizando. No me refiero, nuevamente, a aquellos casos en los que éste es de suyo necesario debido al tema-elecciones, delitos, ejidos, etc.-. Me refiero a aquellos otros en los que aparentemente no existe conexión con el derecho, pero que sin embargo éste determina aspectos relevantes. Si partimos del hecho de que las normas jurídicas regulan las conductas, establecen símbolos de ejercicio del poder, determinan formas sociales de comportamiento y 
otras condiciones semejantes, es claro que en cada tiempo histórico hay una intromisión en los fenómenos que lo constituyan.

Puede suceder que quien quiera analizar el arte, las representaciones pictográficas, la enseñanza para niños, el comercio de lana o el estatus de los viajeros a América, no quiera saber con detalle la totalidad del entramado normativo vigente respecto de su tema. Sin embargo, parecería deseable que supiera cómo es que esas actividades estaban reguladas, pues de otra manera no se comprenderá uno de los aspectos más significativos de su condición. No sabría si la misma es obligatoria o potestativa, si contaba o no con regulaciones y, en su caso, con la posibilidad de sanciones. Algo quedaría por explicar. Deseo que en los próximo 70 años de $H M$, los artículos adopten la perspectiva jurídica. Ello ayudará a iluminar de mejor manera los temas de estudio. 